\title{
Effect of IL-6 and IL-8 on the expression of the complement activation inhibitors MAC-inhibitory protein and decay-accelerating factor in ovarian cancer $\mathbf{A} 2780$ cells
}

\author{
LUCYNA KAPKA-SKRZYPCZAK ${ }^{1}$, SYLWIA POPEK ${ }^{2}$, KRZYSZTOF SAWICKI ${ }^{2}$, \\ EWA WOLIŃSKA ${ }^{3}$, MAGDALENA CZAJKA $^{2}$ and MACIEJ SKRZYPCZAK ${ }^{4}$ \\ ${ }^{1}$ Department of Medical Biology and Translational Research, Faculty of Medicine, \\ University of Information Technology and Management, 35-225 Rzeszow; \\ ${ }^{2}$ Department of Molecular Biology and Translational Research, Institute of Rural Health, 20-090 Lublin; \\ ${ }^{3}$ Department of Pathology, Medical University of Warsaw, 02-091 Warsaw; ${ }^{4}$ Second Department of Gynecology, \\ Medical University of Lublin, 20-954 Lublin, Poland
}

Received December 3, 2015; Accepted May 16, 2016

DOI: $10.3892 / 01.2016 .4795$

\begin{abstract}
The aim of the present study was to evaluate the role of interleukin (IL)- 6 and IL- 8 on the expression of the membrane-bound complement inhibitors membrane attack complex-inhibitory protein (CD59) and decay-accelerating factor (CD55), in the human ovarian carcinoma A2780 cell line, which is a non-producing IL- 6 cell line that does exhibit IL-6 responsiveness, due to the presence of IL- 6 receptors. Extracellular levels of complement system inhibitors were evaluated by western blotting and reverse transcription-quantitative polymerase chain reaction. Cellular localization of CD55 and CD59 in the ovarian cancer cells was assessed by immunofluorescence. The detection of a soluble form of CD55 and CD59 released by the A2780 cells following stimulation with IL-6 and IL-8 was detected by enzyme-linked immunosorbent assay. The present data revealed that A2780 cells express CD55 and CD59 at the mRNA and protein level, but do not secrete these proteins to the culture medium. Results of western blotting demonstrated that the protein level of CD59 was regulated by IL-6 and IL-8 in a dose-dependent manner. Immunofluorescence analysis revealed that the ovarian cancer A2780 cell line expresses the membrane bound form of CD55 protein. The present results indicate that CD55 and CD59 may affect the efficiency of complement-mediated immunotherapies.
\end{abstract}

Correspondence to: Professor Lucyna Kapka-Skrzypczak, Department of Medical Biology and Translational Research, Faculty of Medicine, University of Information Technology and Management, 2 Sucharskiego Street, 35-225 Rzeszow, Poland

E-mail: lucynakapka@gmail.com

Key words: ovarian cancer, complement system, CD55, CD59, IL-6

\section{Introduction}

The complement system is a major component of the innate immune system. Activation of the cascade reaction of the complement system leads to the cytolytic destruction of cancer cells, and it is the primary pathway for protecting the human body from bacterial infections and cancer cells. Decay-accelerating factor (CD55) and membrane attack complex (MAC)-inhibitory protein (CD59) belong to the family of membrane-bound complement regulatory proteins (1). CD59 is a regulatory protein that participates in the inhibition of MAC formation, while CD55 inhibits the formation of C3 and C5 convertases by preventing their cleavage (2). The primary role of CD59 and CD55 is the protection of normal host cells from damage caused by the accidental activation of the complement system (3).

Over-expression of CD59 and CD55 has been observed in a variety of solid tumors, including non-Hodgkin lymphoma and colon, breast and ovarian cancer. An increase in CD55 and CD59 expression has also been associated with a poor response to treatment, an increased tumour stage and shorter disease-free survival time of patients (4-7). Consequently, the activity of complement inhibitors CD59 and CD55 may be associated with the mechanism of cancer cell escape (3).

Ovarian cancer is the fourth leading cause of mortality among women, following breast, lung and colon cancer, and poses a major challenge for treatment, due to late diagnosis, low therapeutic efficiency and increasing chemoresistance. Ovarian cancer is treated by surgery and chemotherapy with a combination of taxanes and platinum $(8,9)$. Complement system activation is a potential target for immunotherapy in ovarian cancer, using complement-activating monoclonal antibodies, and the mechanism of action is associated with complement-mediated cytotoxicity. However, this method may have limited efficacy, due to the expression of natural complement inhibitors present in ovarian cancer cells, including CD55, CD59 and membrane cofactor protein (CD46) (4). Therefore, complement inhibitors may represent the primary cause of 
failure for immunotherapy with monoclonal antibodies. It appears that an improved understanding of the regulatory mechanisms of complement system inhibitor expression, and their function in ovarian and other gynecological cancer, is essential for improving immunotherapy (4).

Cytokines play a major role in the regulation of complement inhibitory protein expression, and are identified in the tumour microenvironment. The key cytokines in this regulation appear to be interleukins- 6 and 8 (IL-6 and IL-8), since increased levels of these cytokines have been identified in the ascites fluid of ovarian cancer patients $(10,11)$. In vitro IL-6 is secreted by mesothelial cells, fibroblasts, macrophages and ovarian tumour cells, while IL- 8 is secreted by endothelial cells and mesothelial cells, monocytes and ovarian tumour cells (11). Therefore, the tumour microenvironment is significant in all processes of ovarian cancer progression.

The primary aim of the present study was to characterize the expression of the complement system inhibitors CD59 and CD55 at the mRNA and protein level in the human ovarian cancer A2780 cell line following IL- 6 and IL-8 stimulation. The present results revealed that CD59 and CD55 proteins present on ovarian carcinoma cells appear to be key factors in protecting malignant ovarian cells from complement-mediated death.

\section{Materials and methods}

Cell culture. The human ovarian cancer A2780 cell line was obtained from the European Collection of Cell Culture (Salisbury, UK). A2780 cells were cultured in RPMI-1640 medium supplemented with L-glutamine, penicillin-streptomycin (10 U/ml-100 $\mu \mathrm{g} / \mathrm{ml}$ ) and 10\% fetal bovine serum (FBS) (all Sigma-Aldrich, Munich, Germany), in a humidified atmosphere of $95 \%$ air and $5 \% \mathrm{CO}_{2}$ at $37^{\circ} \mathrm{C}$. This cell line was selected, since A2780 cells do not produce IL-6, but expresses the IL-6 receptor (12).

Stimulation of cells. Human ovarian carcinoma cells were seeded into petri dishes $\left(5 \mathrm{ml} ; 3 \times 10^{5}\right.$ cells $\left./ \mathrm{ml}\right)$. The cells were washed with phosphate buffered saline (PBS) with $\mathrm{Ca} 2+$ and Mg2+ (Sigma Aldrich, St. Louis, MO, USA) and next were incubated in medium RPMI 1640 supplemented with L-glutamine containing various concentrations of IL-6 and IL-8. Human IL-6 and IL-8 were purchased from Sigma-Aldrich. Subsequent to a $24 \mathrm{~h}$ of incubation, the supernatant was collected and transferred to Eppendorf tubes and frozen at $-80^{\circ} \mathrm{C}$ for subsequent studies. The cells were incubated with $5 \mathrm{mM}$ EDTA in phosphate-buffered saline (PBS) for $10 \mathrm{~min}$. Subsequently, the cells were transferred to new tubes and centrifuged at $12,000 \mathrm{x} \mathrm{g}$ for $10 \mathrm{~min}$ at $4^{\circ} \mathrm{C}$. The supernatant was removed and precipitated cells were stored at $-80^{\circ} \mathrm{C}$.

Cell proliferation assay. The effect of IL-6 and IL- 8 on the proliferation of ovarian cancer cells was determined using a 3-(4,5-dimethylthiazol-2-yl)-2,5-diphenyltetrazolium bromide (MTT) assay. The cells were cultured at a density of $5 \times 10^{3}$ cells per well in 96-well cell culture plates (Nunc ${ }^{\mathrm{TM}}$ MicroWell $^{\mathrm{TM}}$; Thermo Fisher Scientific, Inc., Waltham, MA, USA). Subsequent to a $24 \mathrm{~h}$ incubation, the cells were exposed to various concentrations of IL-6 and IL-8 (1, 10 and $100 \mathrm{ng} / \mathrm{ml})$. In total $96 \mathrm{~h}$ later, the proliferation of the treated cells was assessed using the MTT assay. The amount of formazan dye was determined by quantifying its absorbance at $570 \mathrm{~nm}$ using the FLUOstar Omega Microplate Reader (BMG Labtech $\mathrm{GmbH}$, Ortenberg, Germany). The proliferation rate (PR) was measured by the following equation: PR $(\%)=$ (absorbance of treatment probe / absorbance of control probe) $\mathrm{x} 100 \%$.

Enzyme-linked immunosorbent assay (ELISA). To determine the amount of soluble CD59 and CD55 in the cell medium, an ELISA Kit for Human CD59 glycoprotein and ELISA Kit for Human Complement decay-accelerating factor were used (EIAab Science Co., Ltd., Wuhan, China), according to the manufacturer's protocol.

Reverse transcription-quantitative polymerase chain reaction $(R T-q P C R)$. After a $24 \mathrm{~h}$ stimulation with various concentrations of IL- 6 and IL-8 (1, 10 and $100 \mathrm{ng} / \mathrm{ml})$, total cellular RNA from the cultured cells was isolated using a High Pure RNA Isolation kit (Roche Diagnostics GmbH, Mannheim, Germany), according to the manufacturer's protocol. Extracted RNA was purified and diluted in DNase and RNase free water. Quality and quantity of the isolated RNA was measured by a NanoDrop ${ }^{\circledR}$ spectrophotometer (Thermo Fisher Scientific, Inc.). DNase I (Roche Diagnostic GmbH, Mannheim, Germany) was used when total RNA was isolated (180U per sample) but not when RT-qPCR was performed. The qPCR was performed according to the manufacturer's protocol: TaqMan ${ }^{\circledR}$ Gene Expression Assays Protocol (Applied Biosystems ${ }^{\circledR}$; Thermo Fisher Scientific, Inc.) Complementary cDNA was synthesized from $2 \mu \mathrm{g}$ total RNA using SuperScript II Reverse Transcriptase (Invitrogen $^{\mathrm{TM}}$; Thermo Fisher Scientific, Inc.). Subsequently, $1 \mu \mathrm{l}$ of the resulting cDNA solution was used to amplify cDNA using TaqMan ${ }^{\circledR}$ Gene Expression Assays with specific primers to CD59 (assay ID, Hs00174141_m1) and CD55 (assay ID, Hs00892618_m1), according to the manufacturer's protocol (Applied Biosystems ${ }^{\circledR}$; Thermo Fisher Scientific, Inc.). qPCR was performed in an ABI 7500 Fast Real-Time PCR System (Applied Biosystems ${ }^{\circledR}$ ). Relative CD59 and CD55 expression was measured using the $2^{-(\Delta \Delta \mathrm{Cq})}$ method (13), using $\beta$-actin (assay ID, Hs99999903_m1; Applied Biosystems ${ }^{\circledR}$ ) as the endogenous control. Three independent experiments were performed.

Western blotting. Cells were lysed in RIPA lysis buffer (1\% Tergitol $^{\circledR}, 0.5 \%$ sodium deoxycholate, $0.1 \%$ SDS, $1 \mathrm{mM}$ EDTA, $1 \mathrm{mM}$ EGTA, $1 \mathrm{mM} \mathrm{NaVO}$, $20 \mathrm{mM} \mathrm{NaF,} \mathrm{0.5} \mathrm{DTT,}$ $1 \mathrm{mM}$ PMSF, PIC in PBS). The lysates were centrifuged at $12,000 \mathrm{x} \mathrm{g}$ for $10 \mathrm{~min}$ at $4^{\circ} \mathrm{C}$. The protein concentration was then measured using a Bicinchoninic Acid Protein Assay kit. In total, $20 \mathrm{mg}$ of protein samples were electrophoresed using $10 \%$ sodium dodecyl sulfate polyacrylamide gel electrophoresis under reducing conditions, and transferred to polyvinylidene difluoride membranes. Non-specific binding sites on the membranes were blocked with $5 \%$ skim milk in Tris-buffered saline containing $0.05 \%$ Tween 20 for $1 \mathrm{~h}$ at room temperature, and the membranes were subsequently probed with rabbit polyclonal anti-CD59 (catalog no., sc-28805), mouse monoclonal anti-CD55 (catalog no., sc-59092) and mouse monoclonal $\beta$-actin antibodies (catalog no., sc-47778) (dilution, 1:1,000; Santa Cruz Biotechnology, Inc., Dallas, TX, USA) overnight at $4^{\circ} \mathrm{C}$. This was followed 
by an incubation at room temperature for $1 \mathrm{~h}$ with horseradish peroxidase-conjugated goat anti-rabbit and anti-mouse secondary antibodies (cat nos., sc-2004 and sc-2005, respectively; dilution, 1:2,000; Santa Cruz Biotechnology, Inc.). The membranes were visualized with a chemiluminescence substrate kit (Pierce $^{\mathrm{TM}}$ ECL Western Blotting Substrate; Thermo Scientific, Inc.). Densitometric analysis was performed with Image J version 1.48 software, normalized to $\beta$-actin values.

Immunofluorescence. Cells were grown in 8-well cell culture slides (Nunc ${ }^{\mathrm{TM}}$ MicroWell $^{\mathrm{TM}}$ ) in RPMI-1640 with $10 \%$ FBS. Subsequent to a $24 \mathrm{~h}$ stimulation with various concentration of IL-6 and IL-8 $(1,10$ and $100 \mathrm{ng} / \mathrm{ml})$, the cell culture slides were fixed in $3.7 \%$ formaldehyde for $15 \mathrm{~min}$ and permeabilized in $0.1 \%$ Triton X-100 for $10 \mathrm{~min}$. Following permeabilization, the cell culture slides were blocked in $3 \%$ bovine serum albumin (Sigma Aldrich) for $15 \mathrm{~min}$, and following washing were incubated with mouse monoclonal anti-CD59 (catalog no., ab9182) and anti-CD55 (catalog no., ab1422) antibodies (Abcam, Cambridge, UK) at $10 \mu \mathrm{g} / \mathrm{ml}$ overnight at $4^{\circ} \mathrm{C}$. Subsequently, the cells were incubated at room temperature with a donkey anti-mouse IgG Alexa Fluor ${ }^{\circledR} 488$ conjugated secondary antibody (green fluorescence; catalog no., ab150105; dilution, 1:1,000; Abcam) for $90 \mathrm{~min}$. Fluorescence labeling was analyzed under a fluorescent microscope (BX51; Olympus Corporation, Hamburg, Germany).

Statistical analysis. Statistical analysis was performed with GraphPad Prism 5 software (GraphPad Software, Inc., La Jolla, CA, USA). Multiple comparisons were performed using one-way analysis of variance followed by Tukey's post hoc test. Data are presented as the mean \pm standard deviation. All statistical tests were two-sided and $\mathrm{P}<0.05$ was considered to indicate a statistically significant difference.

\section{Results}

Proliferation of ovarian cancer cells following stimulation by $I L-6$ and $I L-8$. It has been widely reported that IL-6 and IL-8 reinforce the proliferation of ovarian cancer cells (11). However, the present study demonstrated that IL-6 and IL-8 did not affect ovarian cancer A2780 cell proliferation (Fig. 1); subsequent to a $96 \mathrm{~h}$ incubation with IL-6 or IL-6/IL-8 combination, no significant differences were noted between control and treated cells.

IL-6 and IL-8 treatment affects the production of membrane-bound complement regulatory protein CD59 by ovarian cancer cells. Western blotting was performed to investigate the effect of IL- 6 and IL- 8 on the expression of CD55 and CD59 in ovarian cancer A2780 cells. The cells were incubated with various concentrations of IL- 6 alone or IL-6/IL-8 combination. The present results revealed that the cancer cells treated with IL- 6 alone and in combination with IL-8 expressed the membrane-bound complement inhibitor CD59. The protein level of CD59 was increased subsequent to a $24 \mathrm{~h}$ incubation with IL-6, and a $1 \mathrm{ng} / \mathrm{ml}$ concentration of IL- 6 was sufficient to enhance the expression of CD59 (Fig. 2A). However, the level of CD59 was

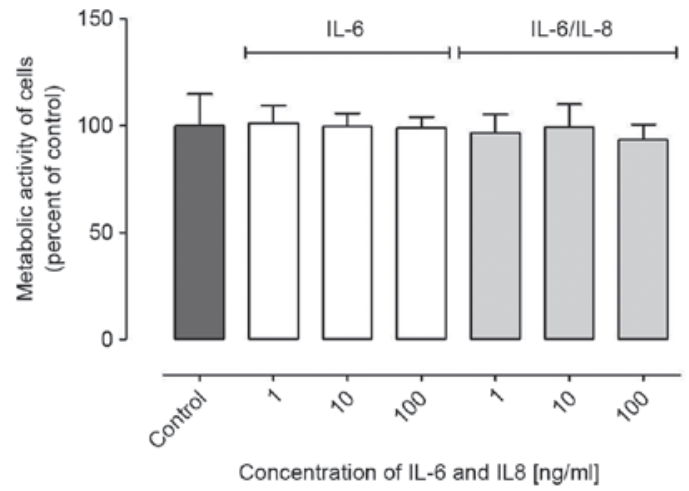

Figure 1. Analysis of pro-proliferative properties of IL-6 and IL-8-treated human ovarian cancer A2780 cells. Proliferation was measured using a 3-(4,5-dimethylthiazol-2-yl)-2,5-diphenyltetrazolium bromide assay and measured as metabolic activity of the cells, which was presented as a percentage of the control. Data are presented as the mean \pm standard deviation. IL, interleukin.

deceased compared with the control following an incubation with $100 \mathrm{ng} / \mathrm{ml}$ IL-6 (Fig. 2A). Abnormal alterations in the protein expression of CD59 were observed when the cells were incubated with IL-6/IL-8 combination; the protein level was decreased following an incubation with $10 \mathrm{ng} / \mathrm{ml}$ IL-6/IL-8 combination (Fig. 2B). These results should be confirmed, since only representative results are presented by the present study.

IL-6 and IL-8 affected the CD59 and CD55 gene expression at the mRNA level in ovarian cancer cells. RT-qPCR was performed to determine the CD55 and CD59 gene expression at the mRNA level. To present the results of relative gene expression, the ${ }^{{ }^{\Delta}} \mathrm{Cq}$ method was used, with $\beta$-actin as the reference gene and non-IL- 6 and IL- 8 treated samples as a control. The mRNA level was analyzed in the same qPCR reaction using a TaqMan probe. The results demonstrated that the relative CD59 expression from the cells at the mRNA level was increased compared with the control following stimulation with IL-6; however, these results were not statistically significant (Table I; Fig. 3A). In samples incubated with IL-6 at $100 \mathrm{ng} / \mathrm{ml}$ the fold change was $\sim 1.5$, which was statistically significant compared with the control $(\mathrm{P}<0.01$; Table I; Fig. 3A). Therefore, the relative expression of CD59 was increased compared with control samples at higher concentrations of IL- 6 treatment. In samples incubated with IL-6/8 combination, no significant differences in expression were observed (Table I; Fig. 3A). The expression of CD55 in samples incubated with IL-6 and IL-6/IL-8 combination was unchanged compared with the control (Table I; Fig. 3B).

Ovarian cancer A2780 cell line expresses the membrane-bound complement regulatory protein CD55. To investigate the membrane-bound form of complement inhibitors CD55 and CD59, A2780 cells were visualized using immunofluorescence. Immunofluorescence was performed using mouse monoclonal anti-CD59 and anti-CD55 primary antibodies, and donkey anti-mouse IgG Alexa Fluor ${ }^{\circledR} 488$ conjugated secondary antibody (green fluorescence). As expected, the expression of CD55 was observed on the surface of the cells 
Table I. Quantitative polymerase chain analysis results for CD55 and CD59 expression in human ovarian cancer A2780 cells treated with various combinations of IL-6 or IL-6/IL-8 combination.

\section{A, CD55}

\begin{tabular}{rrrrr}
\hline \multicolumn{2}{c}{ IL-6 } & & & \multicolumn{2}{c}{ IL-6/IL-8 combination } \\
\cline { 1 - 1 } Concentration, ng/ml & $\mathrm{R} \pm \mathrm{SD}$ & & Concentration, ng/ml & $1.07 \pm 0.36$ \\
\hline 1 & $1.00 \pm 0.30$ & & 1 & $1.21 \pm 0.50$ \\
10 & $1.00 \pm 0.44$ & 10 & $1.10 \pm 0.46$ \\
100 & $1.01 \pm 0.43$ & 100 & $\mathrm{R}$ \\
\hline
\end{tabular}

\section{B, CD59}

\begin{tabular}{rcrrr}
\hline & IL-6 & & \multicolumn{2}{c}{ IL-6/IL-8 combination } \\
Concentration, $n g / m l$ & $\mathrm{R} \pm \mathrm{SD}$ & & Concentration, ng/ml & $1.04 \pm 0.22$ \\
\hline 1 & $1.35 \pm 0.17$ & 10 & $1.11 \pm 0.04$ \\
10 & $1.26 \pm 0.07$ & 100 & $1.11 \pm 0.07$ \\
100 & $1.47 \pm 0.17^{\mathrm{a}}$ & & 1 & $\mathrm{R}$ \\
\hline
\end{tabular}

${ }^{\mathrm{a}} \mathrm{P}<0.01 . \mathrm{R} \pm \mathrm{SD}$, fold change $\left(\mathrm{R}=2^{-\Delta \mathrm{ACq}}\right) \pm$ standard deviation; IL, interleukin; CD55, decay-accelerating factor; CD59, membrane attack complex-inhibitory protein.
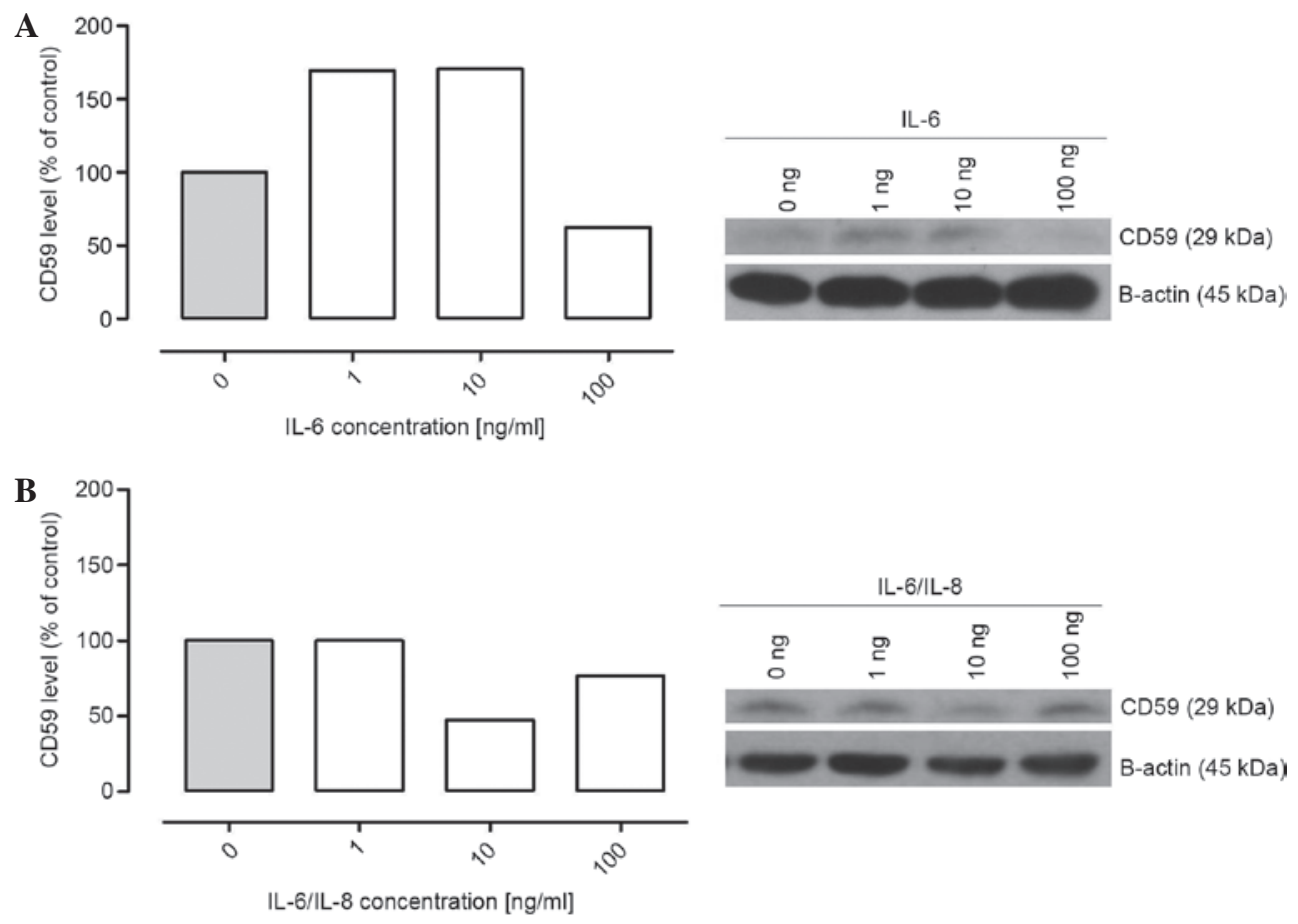

Figure 2. Western blot analysis demonstrating CD59 expression in human ovarian cancer A2780 cells following incubation with various concentrations of (A) IL-6 alone and (B) IL-6/IL-8 combination. The results of densitometric analysis, normalized to $\beta$-actin, are presented as a percentage of control. Data are presented as a representative western blot. IL, interleukin; CD59, membrane attack complex-inhibitory protein; CD55, decay-accelerating factor.

(Fig. 4). However, no differences in fluorescence were observed between cells in cells incubated with IL-6 or IL-6/IL-8 combination compared with control cells (Fig. 4). CD59 was not detected on the cancer cells surface, possibly due to its expression being too low to be detected (data not shown).
A2780 cells do not produce a soluble form of CD55 or CD59 to a significant level. A2780 cell culture was stimulated with various concentrations $(1,10,100 \mathrm{ng} / \mathrm{ml})$ of IL- 6 alone and IL-6/IL-8 combination. Following $24 \mathrm{~h}$, soluble forms of CD55 and CD59 were analyzed in the cell culture supernatants 
A

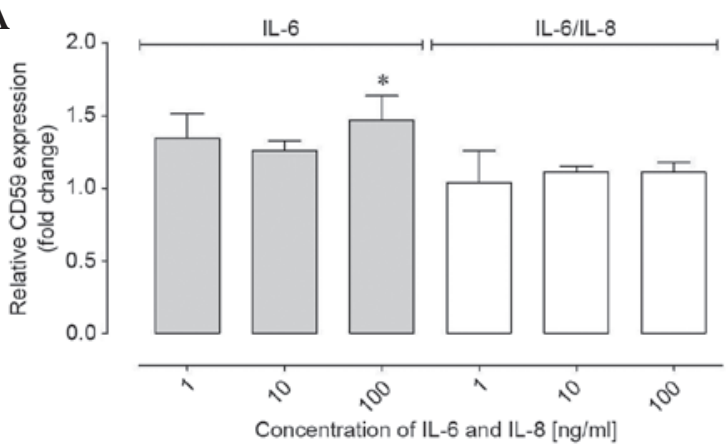

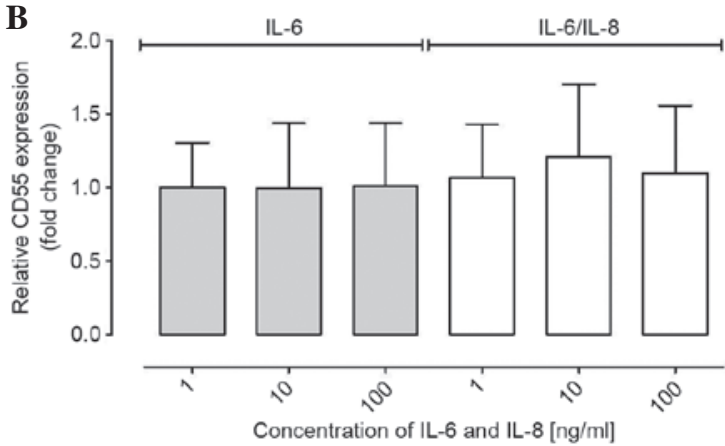

Figure 3. Quantitative polymerase chain reaction analysis of the mRNA expression levels of (A) CD59 and (B) CD55. The graph presents the fold change calculated for the samples incubated with IL 6 and IL 6/IL 8. Sample without interleukin treatment was used as an untreated control and $\beta$ actin was used as a reference gene for normalization. The data are presented as the fold change $\left(\mathrm{R}=2^{\Delta \Delta \mathrm{Cq}}\right)$ mean \pm standard deviation of three independent experiments $(\mathrm{R} \pm \mathrm{SD})$ $(\mathrm{n}=3)$. Statistical significance: * $\mathrm{P}<0.01$. IL, interleukin; CD59, membrane attack complex inhibitory protein; CD55, decay accelerating factor.
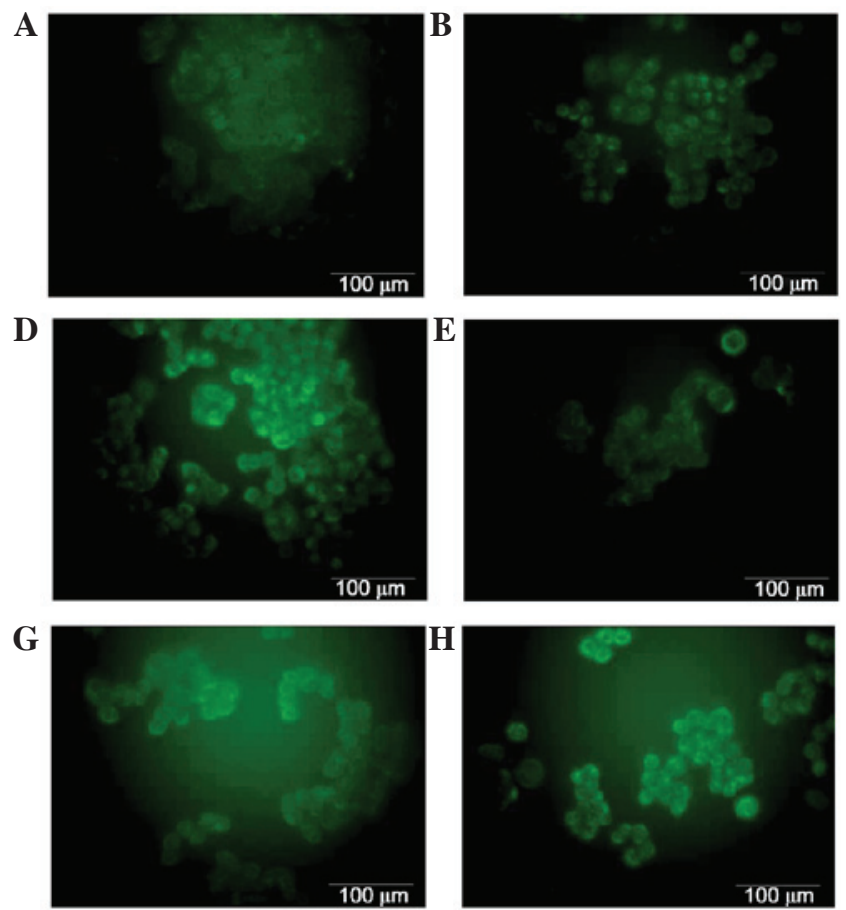
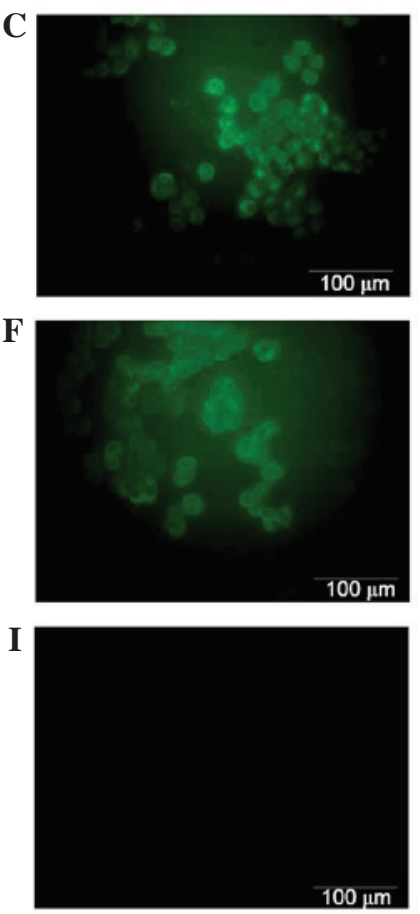

Figure 4. Immunofluorescence staining of decay-accelerating factor protein in human ovarian cancer A2780 cells following a 24 h incubation with various concentrations of IL-6 and IL-6/IL-8 combination. (A) 0, (B) 1, (C) 10 and (D) 100 ng/ml IL-6-treated cells. (E) 0, (F) 1, (G) 10 and (H) 100 ng/ml IL-6/IL-8 combination-treated cells. (I) Control with goat IgG-treated cells (magnification, $x 400)$. IL, interleukin.

with the use of an ELISA method. The two ELISA tests had a detection range of $31.2-2,000.0 \mathrm{pg} / \mathrm{ml}$. The minimum detectable dose of human CD59 and CD55 glycoprotein is typically $<10.7 \mathrm{pg} / \mathrm{ml}$. However in the present study, no CD59 and CD55 glycoproteins were detected (data not shown). It is possible that the concentration of the glycoprotein in the cell culture supernatants was too low to be detected, or that ovarian cancer cells do not release CD55 and CD59 into the microenvironment.

\section{Discussion}

The complement system is an important part of innate immunity. CD59 and CD55 are cell surface-anchored proteins that regulate the activation of complement (3). Cancer cells may protect themselves against complement-dependent cytotoxicity by the expression of complement system inhibitors. The present study investigated the role of IL-6 and IL-8 on CD55 and CD59 expression in the human ovarian cancer A2780 cell line. The present results revealed that IL- 6 affects the expression of CD59 at a protein level; these effects were also detected at the mRNA level of CD59. Relative expression of CD59 was the highest in cells incubated with IL-6 at a concentration of $100 \mathrm{ng} / \mathrm{ml}$ compared with control cells, and these results were statistically significant. However, western blot analysis did not confirm this result; analysis at the protein level revealed that IL- 6 had a positive affect on the CD59 protein expression, but only on samples incubated with

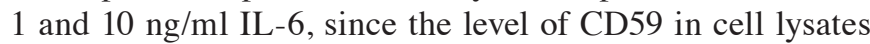
was decreased compared with control cells when incubated with $100 \mathrm{ng} / \mathrm{ml} \mathrm{IL-6.} \mathrm{The} \mathrm{current} \mathrm{study} \mathrm{only} \mathrm{presents} \mathrm{repre-}$ sentative results from western blotting. Furthermore under the 
same experimental conditions, CD59 was not detected on the surface of the cells by immunofluorescence; the fluorescence signal from the CD59 was too weak and was not detectable. Similarly, with regards to the soluble form of CD59, the amount of inhibitor in the culture medium was below the detection limit of the ELISA test used by the present study. Consequently, the present authors hypothesize the existence of other mechanisms that may regulate the expression of CD59 at the post-transcriptional stage. By contrast, expression of CD55 remained relatively unchanged at the mRNA and protein level; however, CD55 was not detected during western blotting and ELISA analysis, only with immunofluorescence and qPCR.

Several studies have addressed the expression of complement system inhibitors in numerous tumors. However, to the best of our knowledge, the role of IL-6 and IL-8 on CD55 and CD59 expression in ovarian cancer cells has not yet been characterized and investigated. Shang et al (7) demonstrated that the expression levels of CD46, CD55 and CD59 were significantly higher in colon cancer tissues compared with normal colon tissues. However, this was independent of the presence of IL-6 and IL-8. Additionally, Wang et al (14) demonstrated that IL-6 and IL-8 may promote cell proliferation in ovarian carcinoma CAOV-3 and OVCAR-3 cells in a time- and dose-dependent manner, and this cell proliferation, induced by IL-6 and IL-8, was suppressed by the use of specific antibodies. However, no significant difference was observed in the proliferation rate of A2780 cells following stimulation by IL- 6 and IL- 8 in the present study. The results differed to those of our study were likely caused by the use of different cell lines and different incubation times. In the study by Wang et al (14) ovarian cancer cell lines CAOV-3 and OVCAR-3 were incubated with IL-6 and/or IL-8 for 24 h, 48 h, 72 h, 96 h and $120 \mathrm{~h}$, and for $48 \mathrm{~h}, 96 \mathrm{~h}$ and $144 \mathrm{~h}$ in CAOV-3 and OVCAR-3 cells, respectively. In the present study the A2780 cancer cells were incubated for $96 \mathrm{~h}$ only. The concentrations of IL-6 and IL- 8 were similar in both studies. The largest effect in Wang et al (14) study was observed after $120 \mathrm{~h}$ incubation with IL-6, IL-8 or both. Additionally, the cell lines used were different in origin, genetic profile and clinical stage, so the influence of IL-6 and IL-8 may be different (15).

Overall, based on the present results, it may be concluded that human ovarian cancer A2780 cells express factors CD55 and CD59, but do not secrete this protein into the tumor microenvironment. The expression of these factors at the protein level appears to be independent on IL-6 and IL-8. However, the mechanism that regulates this process should be investigated further.

\section{Acknowledgements}

The present study was supported by the National Science Centre, based on the decision no. DEC--2011/01/D/NZ7/04688. University of Information Technology and Management, Rzeszow, Poland.

\section{References}

1. Fishelson Z, Donin N, Zell S, Schultz S and Kirschfink M: Obstacles to cancer immunotherapy: Expression of membrane complement regulatory proteins (mCRPs) in tumors. Mol Immunol 40: 109-123, 2003.

2. Alegretti AP, Mucenic T, Tavares Brenol JC and Xavier RM: The role of CD55/CD59 complement regulatory proteins on peripheral blood cells of systemic lupus erythematosus patients. Rev Bras Rheumatol 49: 276-287, 2009.

3. Li J, Gao MH and Zhang B: Inhibition of mutant CD59 protein on proliferation of ovarian cancer A2780 cells. Ai Zheng 28: 379-383, 2009 (In Chinese).

4. Bjørge L, Hakulinen J, Vintermyr OK, Jarva H, Jensen TS, Iversen OE and Meri S: Ascitic complement system in ovarian cancer. Br J Cancer 92: 895-905, 2005.

5. Dzietczenia J, Wróbel T, Mazur G, Poręba R, Jaźwiec B and Kuliczkowski K: Expression of complement regulatory proteins: CD46, CD55, and CD59 and response to rituximab in patients with CD20 (+)non-Hodgkin's lymphoma. Med Oncol 27: 743-746, 2010.

6. Liu M, Yang YJ, Zheng H, Zhong XR, Wang Y, Wang Z, Wang YG and Wang YP: Membrane-bound complement regulatory proteins are prognostic factors of operable breast cancer treated with adjuvant trastuzumab: A retrospective study. Oncol Rep 32: 2619-2627, 2014.

7. Shang Y, Chai N, Gu Y, Ding L, Yang Y, Zhou J, Ren G, Hao X, Fan D, Wu K and Nie Y: Systematic immunohistochemical analysis of the expression of CD46, CD55 and CD59 in colon cancer. Arch Pathol Lab Med 138: 910-919, 2014.

8. Davidson B and Tropé CG: Ovarian cancer: Diagnostic, biological and prognostic aspects. Womens Health 10: 519-533, 2014.

9. Wcisło G and Szczylik C: Preface. In: Ovarian Cancer: Pathobiology, Diagnosis and an Overview of Contemporary Methods of Treatment. Wcisło G and Szczylik C (eds). 1st edition. Termedia, Poznań, pp9, 2011.

10. Kulbe H, Chakravarty P, Leinster DA, Charles KA, Kwong J, Thompson RG, Coward JI, Schioppa T, Robinson et al: A dynamic inflammatory cytokine network in the human ovarian cancer microenvironment. Cancer Res 72: 66-75, 2012.

11. Thibault B, Castells M, Delord JP and Couderc B: Ovarian cancer microenvironment: Implications for cancer dissemination and chemoresistance acquisition. Cancer Metastasis Rev 33: 17-39, 2014

12. Asschert JG, Vellenga E, Ruiters MH, de Vries EG: Regulation of spontaneous and TNF/INF-induced IL-6 expression in two human ovarian-carcinoma cell lines. Int J Cancer 82: 244-249, 1999.

13. Livak KJ and Schmittgen TD: Analysis of relative gene expression data using real-time quantitative PCR and 2(-Delta Delta C(T)) method. Methods 25: 402-408, 2001.

14. Wang Y, Yang J, Gao Y, Du Y, Bao L, Niu W and Yao Z: Regulatory effect of E2, IL-6 and IL-8 on the growth of epithelial ovarian cancer cells. Cell Mol Immunol 2: 365-372, 2005.

15. Beaufort CM, Helmijr JC, Piskorz AM et al: Ovarian cancer cell line panel (OCCP): Clinical importance of in vitro morphological subset, PLoS One 9, e103988, 2014 